\title{
Study of the Transient Behavior of Turbocharged Diesel Engines Including Compressor Surging Using a Linearized Quasi-Steady Analysis
}

\author{
C.D. Rakopoulos, C.N. Michos and E.G. Giakoumis \\ Mechanical Engineering Department, National Technical University of Athens
}

Copyright (C) 2005 SAE International

\begin{abstract}
The transient operation of turbocharged diesel engines during turbocharger compressor surging is investigated through simulation. This form of compressor dynamic instability can generate large amplitude compressor mass flow and pressure rise oscillations, sometimes leading even to flow reversals, and may also induce severe torsional loading to the turbocharger shaft. A model predicting the dynamic behavior of the engine aircharging system when compressor surging occurs was developed in conjunction with a linearized quasi-steady diesel engine simulation code. This analysis possesses the advantage over the more detailed engine codes of basic simplicity, speed of calculation and no need of many engine and turbocharger components parameters given as input data. Emphasis is given to the correct modeling of the physics of the phenomena concerned. Transient operation runs, including critical cases for surging initiation, were applied for two similar six-cylinder diesel engines. The first one is a Ruston \& Hornsby engine for light duty automotive diesel applications, while the second one is a MWM marine duty diesel engine. By analyzing simulation results, the effect of the engine inlet manifold volume and the compressor air duct length on the phenomenon of surging is studied.
\end{abstract}

\section{INTRODUCTION}

The appropriate selection of a turbocharging system and the correct matching between the engine and the turbocharger are essential for obtaining good steady state as well as transient performance of the turbocharged diesel engine. Apart from operation of the compressor on its performance map within the region of maximum efficiency, it is vital that for all operating points of the engine the surge margin is adequate for avoiding compressor surging.

Moreover, engine transient response can be of great importance, especially when the engine operates close to or at full load, where the compressor operating point is located near to the surge limit. In special dynamic operating conditions, turbocharger compressor surging may occur. Therefore, it is strongly desired to ensure that both the engine and turbocharger are operating away from these detrimental conditions. At this point, engine performance prediction codes can be very useful for investigating the engine and turbocharger transient behavior during this complex phenomenon and thus avoiding recourse to be made to costly and timeconsuming measuring techniques in order to obtain the relevant results.

An initial approximate attempt to model the diesel engine air-charging system was attempted in [1], in order to study surging phenomena produced by the opening and closing of the cylinders' scavenging ports. In a similar approach to assess the dynamic response of a compression system during compressor instability, a theoretical model was developed in [2]. This analysis reported the time dependent behavior of an axial flow compression system when surge or rotating stall occurs, and numerical results were compared and found quantitatively adequate with experimental data presented in [3]. In [4], the model developed in [2] for axial compressors was shown to give a satisfactory description of surge oscillations in a centrifugal compression system too. The assumption in previous treatments of constant compressor rotor speed during surge was relaxed in [5], by taking into account the compressor shaft speed dynamics, thus improving model's agreement with observed surge behavior.

So far, several sophisticated engine simulation codes have been developed for the prediction of the transient behavior of various diesel engines and their turbocharging systems, a few of them including compressor surging. In [6], a zero-dimensional engine simulation code is used for investigating transient performance of a sequentially turbocharged marine diesel engine, with a special focus on compressor surging, incorporating the model presented in [2]. A similar detailed reciprocating engine performance prediction code of the 'control volume' type is utilized in [7], in order to study the diesel engine transient operation during turbocharger compressor surging. That work extended the model in [5] by taking into account the air 
dynamics in the compressor inlet ducting and considered the open thermodynamic system concept [8] for the modeling of the engine inlet manifold.

In this work, the model for the simulation of the dynamic behavior of the compression system when compressor surging occurs, presented in [5], is adopted. In order to more accurately represent the compression system discharge plenum's processes, the model proposed in [7] for the inlet plenum is used instead of assuming isentropic processes taking place in it [2]. Furthermore, as the complete compressor map is needed for the description of surge cycles, a simple method for estimating the compressor characteristics in the region to the left of the surge line is presented, when only the useful operational range of the compressor between the surge limit and the choking region is known. In addition to that, the compressor torque must also be estimated for each point of the compressor map and a short and direct way is proposed.

In an attempt to simplify the simulation model at the point of the compressor dynamic behavior and consequently save efforts and computing time, it is assumed that the pressure rise-compressor mass flow rate relationship is the same under transient conditions as it is at steady state, i.e. the compressor responds quasi-steadily to changes in mass flow. Although this linearized approach ignores the departure of the compressor characteristics from their steady state form observed under transient conditions, which is expressed by a first order differential equation [2,7], it makes the model more easily applicable to various compressors. This is because it releases itself from the necessity of inserting specific compressor geometric parameters as input data, needed in the previously mentioned equation.

At this point, the developed model for the study of the transient behavior of the diesel engine air-charging system during turbocharger compressor surging is combined with a linearized quasi-steady engine simulation code. The directness of the engine model, escorted with satisfactory accuracy of the analysis results, enables its use for simulating turbocharged diesel engines without excessive requirements of data insertion. Thus, the increased mathematical complexity that the more refined phenomenological models necessitate is avoided.

The transient behavior of a Ruston \& Hornsby, sixcylinder diesel engine, the data of which is taken from the open literature, was examined, when running under operating conditions dangerous for surging generation. This analysis was also applied to a similar MWM, sixcylinder diesel engine located at the authors' laboratory, using its measured data at steady state and transient conditions, in order to investigate the time dependent behavior of the system encountered during the surge cycles. Also, a parametric investigation was made in order to determine the effects of each compression system element on the surging. Specifically, the volume of the inlet plenum and the duct length supplying the compressed air from the compressor discharge to the inlet plenum were independently varied, and so their influence on the transient behavior of the system was revealed.

\section{THEORETICAL COMPRESSION SYSTEM MODELING}

\section{MODEL DESCRIPTION, ASSUMPTIONS AND FUNDAMENTAL EQUATIONS}

A common simplified schematic of an actual six-cylinder turbocharged diesel engine centrifugal compression system is depicted in Figure 1. It includes the centrifugal compressor with its inlet and outlet ducting, which discharges the compressed air into the engine inlet manifold. Usually, an air cooler is fitted between the compressor and the inlet manifold for reducing the temperature of the compressor discharge air. The inlet manifold is then connected with the engine cylinders via the inlet valves or ports. In the case of a turbocharged engine, the compressor is driven by the exhaust gasdriven turbine, both being mounted on the turbocharger shaft.

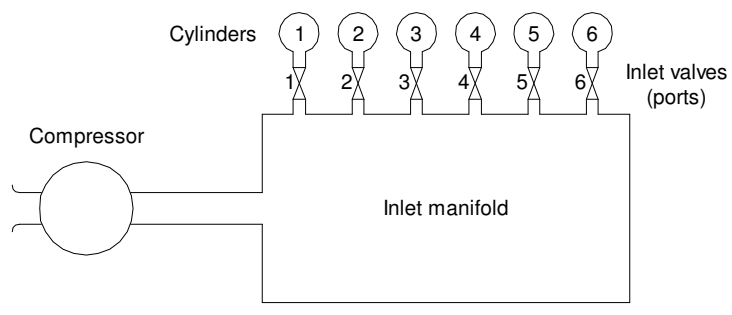

Figure 1. Simplified schematic of an actual six-cylinder turbocharged diesel engine centrifugal compression system.

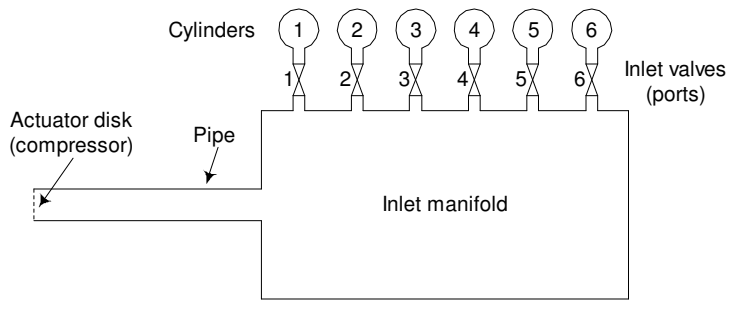

Figure 2. Equivalent arrangement of compression system.

In order to model the actual compression system, the equivalent arrangement, presented in Figure 2, firstly proposed in [2] is adopted here. According to this approach, the compressor is replaced by an actuator disk with zero length, across which the air pressure rises, while its ducting is replaced by a constant area pipe, connecting the compressor discharge with the inlet manifold entrance, to account for the dynamics of the fluid in the compressor passages and its ducting. For the sake of simplicity of the presented model, the compressor inlet ducting is not included into the simulation. This simplification does not introduce 
significant errors to the results, when the compressor inlet is relatively short and of small volume [9]. As a result, the compressor inlet temperature and pressure variations noticed during surge cycles [3] are neglected, and it is supposed that the air that is supplied to the compressor impeller for raising its pressure is constantly at ambient conditions.

It is assumed that the compressor always satisfies its steady flow characteristics, provided by the compressor manufacturer and derived under steady state conditions, responding under dynamic conditions just as it does under steady state. According to the model, the steady state compressor map, which is supposed to apply at all engine operating conditions, is accessed with the values of compressor mass flow parameter and speed parameter, while the compressor pressure ratio is calculated using two-dimensional interpolation of data. A digital representation of its steady state map is used for this purpose. Compressor rotational speed during surge is variable and is calculated from the turbocharger shaft speed dynamics. It is determined from the balance of the torque delivered from the turbine wheel on the turbocharger shaft during the expansion of the exhaust gases to ambient pressure and the one absorbed by the compressor wheel for the compression of the inducted air, including the torque needed to overcome turbocharger shaft bearings friction. Application of the conservation of angular momentum on the turbocharger shaft gives the following equation:

$$
\mathrm{I}_{\mathrm{TC}} \frac{\mathrm{d} \omega_{\mathrm{TC}}}{\mathrm{dt}}=\mathrm{M}_{\mathrm{t}}-\mathrm{M}_{\mathrm{C}}
$$

where

$$
\mathrm{I}_{\mathrm{TC}}=\mathrm{I}_{\mathrm{t}}+\mathrm{I}_{\mathrm{C}}+\mathrm{I}_{\mathrm{TC} \text { shaft }}
$$

and $\mathrm{I}_{\mathrm{TC} s h a f t}$ is the inertia of the turbocharger shaft alone.

Regarding the compressor air duct, this is treated as a column of air and no consideration is made of changes in velocity or pressure of air flow along the duct at any instant. Therefore, one-dimensional incompressible flow is assumed. The geometry of this equivalent duct is determined by requiring that a given rate of change of mass flow produces the same unsteady pressure difference in the actual duct and in the model, and by matching the constant flow-through area of the model duct with a characteristic area of the actual duct. This can be taken, in the case of a centrifugal compression system, as the compressor impeller inlet-eye area. The above requirement leads to the relation (where the integral below extends over the compressor and its outlet duct):

$$
\left(\frac{\mathrm{L}_{\mathrm{c}}}{\mathrm{A}}\right)_{\operatorname{model}}=\int \frac{\mathrm{d} \ell}{\mathrm{A}(\ell)}
$$

Pressure losses across the duct are not taken into account. Conservation of momentum in this equivalent pipe provides the following differential equation:

$$
\frac{d \dot{m}_{c}}{d t}=\frac{p_{c}-p_{i}}{L_{c} / A}
$$

where

$$
\mathrm{p}_{\mathrm{c}}=\mathrm{pr} \cdot \mathrm{p}_{\mathrm{a}}
$$

is the compressor discharge pressure and 'pr' is the compressor pressure ratio. In that way, the inertia of the air contained inside the compressor impeller, diffuser, volute and outlet ducting is taken into account.

As far as the engine inlet manifold is concerned, it is treated as a constant volume open thermodynamic system, where the mass of gas can increase or decrease with time (the so-called 'filling and emptying' model). Only its volume is considered, with its geometrical profile dropped out of consideration, while pressure loss at its entrance is disregarded. The equations that govern such systems are the conservation of mass and the conservation of energy. So, neglecting heat losses through the manifold walls and assuming a perfect gas with constant specific heats, the conservation of energy yields for the manifold pressure the following differential equation:

$$
\frac{d p_{i}}{d t}=\frac{\gamma R}{V_{i}}\left(\dot{m}_{c} T_{c}-\dot{m}_{e} T_{i}\right), \quad \text { with } \dot{m}_{c}>0
$$

where $\dot{m}_{e}$ is the air mass flow inducted into the engine cylinders through the inlet valves or ports. This equation is applicable only for the normal compressor flow operation. On the contrary, in the case of reverse flow compressor operation, Equation (4) becomes:

$$
\frac{d p_{i}}{d t}=\frac{\gamma R}{V_{i}}\left(\dot{m}_{c} T_{i}-\dot{m}_{e} T_{i}\right), \quad \text { with } \quad \dot{m}_{c}<0
$$

For the accumulated masses in the inlet manifold, application of the conservation of mass yields:

$$
\frac{d m_{i}}{d t}=\dot{m}_{c}-\dot{m}_{e}
$$

According to the agreed convention, mass flows entering and exiting an open thermodynamic system are considered having positive and negative values, respectively. The modeling of the inlet manifold is completed by using the perfect gas law, in order to calculate the manifold temperature: 


$$
T_{i}=\frac{p_{i} V_{i}}{m_{i} R}
$$

\section{REPRESENTATION OF THE COMPRESSOR} CHARACTERISTICS TO THE LEFT OF THE SURGE LINE AND COMPRESSOR TORQUE

The presented model requires as input data the complete steady state compressor characteristics, that is, except for the normal compressor flow region, the area to the left of the surge line. This is necessary in order to predict the position of the compression system operating point on the compressor performance map during the oscillatory surge cycles, especially when the compressor flow reverses. It is a conventional way to plot the stable compressor operating zone in terms of pressure ratio against mass flow parameter for various lines of constant rotational speed parameter and this is normally provided by the compressor manufacturer. To obtain the unstable region of the compressor performance map experimental work can be useful [4,5]. Nonetheless, in order to avoid recourse to be made to experiments, a simple method for estimating the complete compressor characteristics is presented, when only the useful operational range of the compressor between the surge limit and the choking region is known.

The region of the compressor map between zero mass flow and the surge line is represented by the following cubic polynomial:

$$
\operatorname{pr}=\operatorname{pr}_{0}+\beta\left[1+\frac{3}{2}\left(\frac{\mathrm{m}_{\mathrm{par}_{\mathrm{c}}}}{\varphi}-1\right)-\frac{1}{2}\left(\frac{\mathrm{m}_{\mathrm{par}_{\mathrm{c}}}}{\varphi}-1\right)^{3}\right]
$$

A third order polynomial equation for this area of the compressor map was suggested in [4], in order to fit experimental data for a small centrifugal compressor, and used in [10] for a theoretical analysis in axial compression systems. The parameters $\beta$ and $\varphi$ can be seen in Figure 3, while $\mathrm{pr}_{0}$ is the compressor pressure ratio at zero mass flow and the compressor mass flow parameter is:

$$
\mathrm{m}_{\mathrm{par}_{\mathrm{c}}}=\dot{\mathrm{m}}_{\mathrm{c}} \sqrt{\mathrm{T}_{\mathrm{a}}} / \mathrm{p}_{\mathrm{a}}
$$

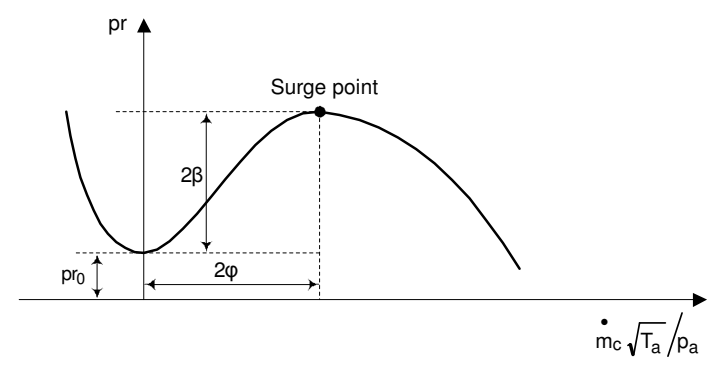

Figure 3. Compressor characteristic showing the definition of parameters $\beta$ and $\varphi$.
Concerning Figure 3 , it should be mentioned that the point on a constant speed line on the compressor map where surge occurs depends on whether the compressor diffuser has vanes or not. Surge occurs when the slope of the speed line is zero or slightly positive, with vaneless diffusers, or slightly negative, with vaned diffusers.

Due to the fact that the compression system operating point during surge passes through this zone quite rapidly, as very abrupt mass flow excursions are observed at almost constant pressure, this part of the compressor characteristics does not greatly affect the prediction of the compression system transient behavior.

For the pressure ratio at compressor zero mass flow, the equation used in [11] and [7] is adopted here:

$$
\operatorname{pr}_{0}=\left[1+\frac{\gamma-1}{2 \gamma R T_{a}} \omega_{c}{ }^{2}\left(r_{2}{ }^{2}-r_{1}{ }^{2}\right)\right]^{\gamma / \gamma-1}
$$

where $r_{1}$ and $r_{2}$ are the compressor eye and impeller outer radii, respectively. Referring to the compressor eye radius, this is defined as the compressor impeller eye mean geometric radius, which divides the impeller eye area into two sections of equal area:

$$
r_{1}=\sqrt{\frac{r_{h 1}^{2}+r_{t 1}^{2}}{2}}
$$

where $r_{h 1}$ and $r_{t 1}$ are the impeller eye hub and tip radii, respectively.

Experimental work [4] has shown that the negative flow branch of a centrifugal compressor characteristic can accurately be matched with a parabola. In [6] and [7] the following equation was presented and is also used here:

$$
\mathrm{pr}=\mathrm{pr}_{0}+2 \beta\left(\dot{\mathrm{m}}_{\mathrm{c}} / 2 \varphi\right)^{2}
$$

with reference to Figure 3 , where the compressor characteristic parameters $\beta$ and $\varphi$ are identified.

Another basic element of the developed model is the calculation of compressor torque for each operating point of its performance map. Application is made of the first law of thermodynamics in the form of the steady flow energy equation to a control volume around the compressor. Thus, by neglecting heat losses and taking into account the definition of compressor isentropic efficiency [8], the following equation is derived for the assessment of the compressor absorbed torque [7]:

$$
\mathrm{M}_{\mathrm{c}}=\frac{30 \gamma \mathrm{R} \dot{\mathrm{m}}_{\mathrm{c}} \mathrm{T}_{\mathrm{a}}}{\pi \mathrm{N}_{\mathrm{c}}(\gamma-1) \eta_{\mathrm{c}}}\left(\mathrm{pr}^{(\gamma-1) / \gamma}-1\right)
$$


where the compressor rotational speed is expressed in rpm.

Thus, it is obvious that in order to calculate the compressor torque, for a certain compressor shaft speed and air mass flow, one should estimate the compressor pressure ratio and isentropic efficiency from its performance map. It is reminded that these variables are extremely non-linear functions of the compressor mass flow and the turbocharger shaft speed. As mentioned before, this model assesses the compressor pressure ratio using a two-dimensional interpolation of data from the digital representation of the compressor steady state map. In order to simplify the compressor torque calculation procedure, since this is performed many times during the present simulation, it is preferable to substitute the calculation based on isentropic efficiencies, and thus avoid another interpolation, by converting the usual compressor characteristics into compressor torque parameter to compressor speed parameter.

A simple and direct way is proposed for this purpose. For each point of the compressor stable region the compressor torque is calculated using Equation (10). Then, the compressor torque parameter $M_{c} / p_{a}$ is divided by the compressor speed parameter $\mathrm{N}_{c} / \sqrt{\mathrm{T}_{\mathrm{a}}}$, forming the variable $\mathrm{M}_{\mathrm{c}} \sqrt{\mathrm{T}_{\mathrm{a}}} / \mathrm{N}_{\mathrm{c}} \mathrm{P}_{\mathrm{a}}$. Plotting the previous variable against the compressor mass flow parameter for all lines of constant compressor speed parameter, it results to a straight line that can easily be fitted to the calculated points $[12,17]$, thus giving:

$$
\mathrm{M}_{\mathrm{c}} \sqrt{\mathrm{T}_{\mathrm{a}}} / \mathrm{N}_{\mathrm{c}} \mathrm{p}_{\mathrm{a}}=\mathrm{a} \cdot\left(\dot{\mathrm{m}}_{\mathrm{c}} \sqrt{\mathrm{T}_{\mathrm{a}}} / \mathrm{p}_{\mathrm{a}}\right)+\mathrm{b}
$$

It is stated that the range of values of compressor mass flow parameter in the above function extends from the choking area to the zero mass flow point. In this way, by knowing the values of the constants $a$ and $b$ beforehand, and inserting them into the model as input data, the compressor torque calculation is greatly facilitated. Although this procedure saves computing time and effort, it is apparent that the necessary data for the calculation remain the same.

Regarding the reverse flow compressor zone, it is proposed to apply the even extension of Equation (11) for the calculation of the compressor torque.

\section{LINEARIZED QUASI-STEADY TURBOCHARGED DIESEL ENGINE MODELING}

The developed model for the simulation of the compression system transient behavior during compressor surging was then incorporated into a linearized quasi-steady engine code. The use of such codes of limited complexity is justified by their usefulness of identifying key controlling variables, to provide guidelines and determine trends of engine control design, accompanied with adequate accuracy of the predicted results. In any case, it is not within the scope of this work to recourse to more elaborate, but laborious engine performance prediction codes. The speed and compactness characterize such models, whilst still retaining considerable sophistication and precision [12].

Quasi-steady codes model the various components of the overall simulated system in terms of their steadystate characteristic, meaning that each of them passes successively from one steady state operating point to another. The intermittent nature of the engine operating cycle is neglected and many cyclical phenomena, such as the oscillatory intake flow into the engine cylinders and the fluctuating pressure and temperature occurring in the exhaust manifold, are approximately represented by time averaged values. Mean-value engine simulation models, like the one presented here, are more eventbased rather than time-based, since the flow related parameters are less varying in the event domain. It is essential that the relationship between the mass flow parameter and the pressure ratio is available for each component of the system. These data are typically supplied in the form of component characteristics for the rotodynamic machinery, while they are less readily available for the engine, which needs power output and temperature rise data in order to be modeled. For the derivation of such engine codes, some assumptions usually need to be made. Also, empirical data possibly included are generally specific to a particular engine, rendering it difficult to extrapolate results far beyond the database available.

Further down, the main assumptions made to derive this model are presented. According to this code, the working medium in the various components of the overall engine model is considered to be either pure air or exhaust gas, both regarded as perfect gases with constant specific heats. Due to the relatively low gas velocities involved, the differences between static and dynamic pressures and temperatures are neglected. In case where an air cooler is fitted downstream the compressor, the air pressure drop across its pipes is considered insignificant. Heat transfer through the inlet manifold walls is neglected, while the air that is contained inside the manifold is considered spatially uniform. Calculation of the air flow through the inlet valves is not proceeded in small steps at specific time increments, during the period from their opening until their closure at the engine operating cycle, since the code time scale is much longer. Instead, the air mass flow from the inlet manifold into the cylinders is determined by the speed-density equation. Furthermore, transport and time delays, which are actually important in more complete engine simulation codes, have not been incorporated at this stage. Also, combustion related sophisticated considerations have been neglected. In a more detailed simulation code, the modeling of the exhaust valves and exhaust manifold might be included too, but these items can be disregarded in a quasi-steady analysis for studying surging phenomena. 
When an air cooler is employed for the cooling of the compressor discharge air, the exit temperature is calculated using the air cooler effectiveness and the appropriate compressor discharge and coolant medium temperatures from the following equation:

$$
\mathrm{T}_{\mathrm{ac}}=\varepsilon \mathrm{T}_{\text {cool }}+(1-\varepsilon) \mathrm{T}_{\mathrm{c}}
$$

Regarding the modeling of the engine block, the crankshaft dynamics can be expressed with the conservation of angular momentum [13], getting:

$$
\mathrm{I}_{\text {tot }} \frac{\mathrm{d} \omega_{E}}{\mathrm{dt}}=M_{\mathrm{b}}-M_{\ell}
$$

where

$$
\mathrm{I}_{\text {tot }}=\mathrm{I}_{\mathrm{E}}+\mathrm{I}_{\ell}
$$

The engine brake torque

$$
M_{b}=M_{\text {ind }}-M_{f r}
$$

is defined as the difference between the cylinders indicated torque $M_{\text {ind }}$, which is assumed proportional to the injected fuel mass per stroke, and the engine friction torque $M_{f r}$, which is suggested to be a linear function of the engine speed.

As already stated above, the air mass flow into the engine cylinders is calculated by the speed-density equation [14]:

$$
\dot{\mathrm{m}}_{\mathrm{e}}=\lambda \frac{\mathrm{p}_{\mathrm{ivc}}}{R \cdot \mathrm{T}_{\mathrm{ivc}}} \mathrm{v}_{\mathrm{tr}} \mathrm{z} \frac{\mathrm{N}_{\mathrm{E}}}{120}
$$

where the scavenge ratio is assumed to have a fixed value, $p_{i v c}$ and $T_{i v c}$ are the air pressure and temperature at inlet valve closing, respectively, the engine rotational speed is expressed in rpm and $V_{t r}$ is the trapped volume per cylinder. The latter one means that not all of the swept cylinder volume is filled with air during the induction stroke, but only a portion of it, since the inlet valve closes some degrees crank angle above bottom dead center.

Furthermore, for the engine model to be developed, engine temperature rise data must be included. It is mentioned that engine temperature rise is strongly dependent on the overall air-fuel ratio, with engine speed having only a minor effect [15].

The fuel pump characteristics have been simplified to a single relation connecting the injected fuel mass per stroke for all cylinders with the fuel pump rack position. This equation is supposed to apply for the whole engine speed and load range.
Also, in order to enable the model to be used for transient engine simulations, an engine speed governor is included. The governor controls the fuel pump rack position, which in turn defines the injected fuel mass into the engine cylinders, so determining engine speed at various loads. The governor used in steady state simulations of the model is an isochronous one, achieving zero speed droop, representing a proportional plus integral controller and obeying the PI control law with first order dynamics [12]:

$$
q_{t}=q_{t-1}+\frac{\left[k_{P}\left(N_{E_{d e m}}-N_{E}\right)-q_{t-1}\right] \Delta t}{\tau_{g}}+\int_{0}^{t} k_{l}\left(N_{E_{d e m}}-N_{E}\right) d t
$$

During engine transient simulations, the integral term in Equation (15) is normally omitted, unless otherwise mentioned, thus failing to maintain constant engine speed.

The turbocharger turbine is included in the simulation using a digital representation of its characteristics. Turbine expansion ratio is mapped versus its swallowing capacity, turbocharger speed being a parameter, while turbine isentropic efficiency is represented by a single line (independently of turbocharger speed) against blade speed ratio. It is noted that turbine expansion ratio is corrected by a pulse factor, in an attempt to take into account the pulsating nature of exhaust gas flow exiting the engine cylinders [16].

\section{DESCRIPTION OF THE ENGINES}

The overall developed simulation code was used for the study of the transient behavior of two similar six-cylinder, four-stroke, turbocharged diesel engines, including dangerous cases for surge initiation. The first of them is a Ruston \& Hornsby 6YEX Mk II, 11.3 Liters, light duty, turbocharged diesel engine, similar to those used in truck and bus applications [17]. The second one is a MWM TbRHS 518S, 16.6 Liters, marine duty, turbocharged diesel engine, of a little more limited speed range than the former one.

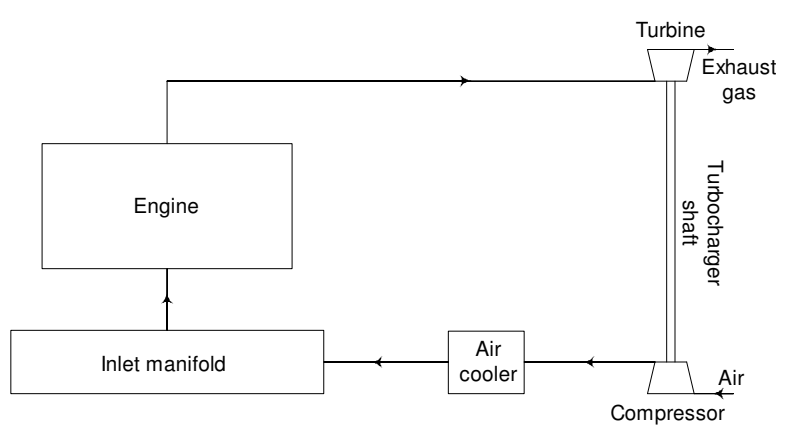

Figure 4. Basic simulated elements of engine configurations.

The basic elements used in the simulation for both engines are shown in Figure 4. The main difference 
between the two engine configurations is that the MWM engine is equipped with an air cooler, unlike the Ruston \& Hornsby engine. Both engines employ the pulse turbocharging system, using a double entry, single-stage, radial, fixed geometry turbine and a single-stage, radial compressor. The Ruston \& Hornsby engine is equipped with a 'Holset' turbocharger, while the MWM engine with a 'KKK' one. Tables 1 and 2 provide the main parameters of the two engines.

Table 1. Ruston \& Hornsby 6YEX Mk II engine parameters

\begin{tabular}{|l|l|}
\hline Number of cylinders & 6 \\
\hline Displacement volume & $11.325 \mathrm{It}$ \\
\hline Bore & $127 \mathrm{~mm}$ \\
\hline Stroke & $149 \mathrm{~mm}$ \\
\hline Connecting rod length & $286 \mathrm{~mm}$ \\
\hline Compression ratio & 14.4 \\
\hline Turbocharger & $1 \mathrm{Holset} 4 \mathrm{LEV}-305$ \\
\hline Operating speed range & $1000-1800 \mathrm{rpm}$ \\
\hline Power output & $170 \mathrm{~kW} \mathrm{@} 1800 \mathrm{rpm}$ \\
\hline Maximum torque & $900 \mathrm{Nm}$ \\
\hline
\end{tabular}

Table 2. MWM TbRHS 518 S engine parameters

\begin{tabular}{|l|l|}
\hline Number of cylinders & 6 \\
\hline Displacement volume & $16.625 \mathrm{It}$ \\
\hline Bore & $140 \mathrm{~mm}$ \\
\hline Stroke & $180 \mathrm{~mm}$ \\
\hline Connecting rod length & $350 \mathrm{~mm}$ \\
\hline Compression ratio & 17.7 \\
\hline Turbocharger & $1 \mathrm{KKK} \mathrm{M4B} \mathrm{754/345}$ \\
\hline Operating speed range & $1000-1500 \mathrm{rpm}$ \\
\hline Power output & $228 \mathrm{~kW} \mathrm{@} \mathrm{1500} \mathrm{rpm}$ \\
\hline Maximum torque & $1455 \mathrm{Nm}$ \\
\hline
\end{tabular}

In the next section, simulation results will be presented, firstly for the Ruston \& Hornsby and then for the MWM engine.

\section{PRESENTATION OF THE RESULTS AND DISCUSSION}

\section{RUSTON \& HORNSBY 6YEX MK II ENGINE}

The steady state, transient with surge, and parametric surge behavior of this engine is exposed below.

\section{Steady state}

Initially, steady state simulation runs were performed at full load for the whole operating engine speed range. Engine steady state performance at full load is of great concern with regard to the compressor surging, as it determines how close to the surge line, on the compressor map, the engine most critical operating points are. Some predicted results, derived from calculations within the engine simulation program, presenting the turbocharged engine performance at full load are shown in Figure 5. They include the engine brake power, the brake specific fuel consumption, the compressor pressure ratio, the air mass flow, the air-fuel ratio and the turbocharger speed.
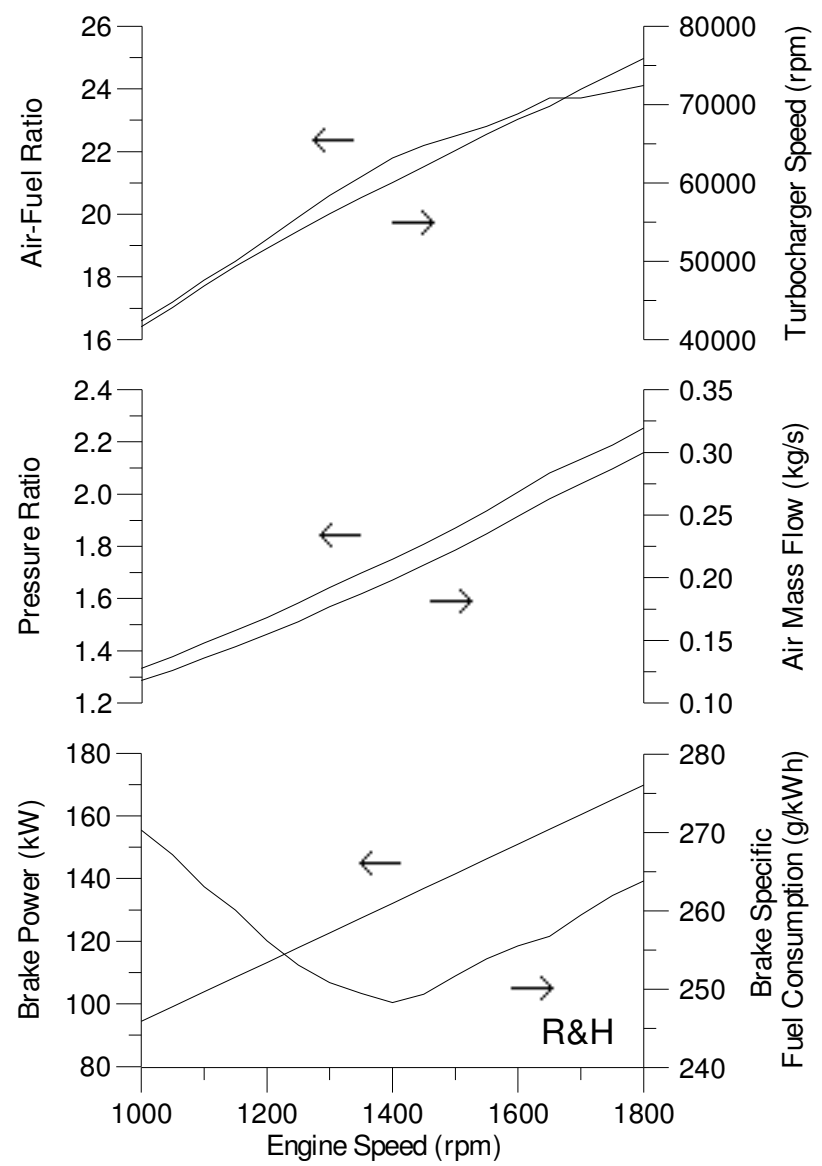

Figure 5. Predicted steady state results at full load.

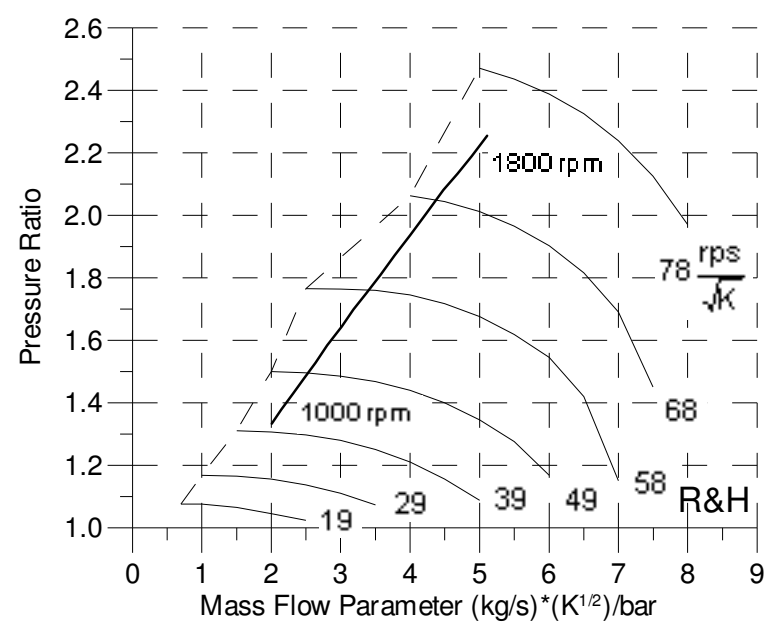

Figure 6. Predicted engine full load operating line superimposed on the compressor map. 
Furthermore, the predicted engine full load operating line, superimposed on the compressor map, is depicted in Figure 6.

At first view, it seems that the full load operating points for all engine speeds do not have exactly the same surge margin. However, the matching between engine and turbocharger may be considered adequate under normal engine operating conditions, as no engine operating point lies too close to the surge line.

\section{$\underline{\text { Transients with surge }}$}

After computing the predicted engine steady state operation, a transient simulation case where turbocharger compressor surging may occur was examined. According to this, the engine operates at full load, when the injected fuel into the engine cylinders is somehow rapidly reduced. As a result, the engine torque is correspondingly reduced and since the engine load does not immediately drop to match the engine torque, the engine speed quickly decreases. Thereby, engine airflow also drops, while turbocharger speed and boost pressure retain their relatively high values from the previous steady operation at full load, due to the inertia of the turbocharging system. This includes the inertia of the turbocharger rotating parts, which delays the turbocharger shaft deceleration, and the volume of inlet and exhaust manifolds, which need some time to empty and fill again with working medium equivalent to the new operating point. In that way, the compressor may pass its stable limit and surging may be generated.

Such an extreme engine operation case, which caused compressor surging, was simulated using the developed model. Some representative predicted engine and compressor parameters are shown in Figures 7 and 8 , respectively, plotted for time periods that are significant for the description of the phenomenon, while Figure 9 shows the predicted trajectory of the inlet manifold to ambient pressure ratio against the compressor mass flow parameter on the compressor performance map.

According to this case, the engine was operating at full load and $1300 \mathrm{rpm}$. Then, the rack position was reduced from $100 \%$ to almost $20 \%$ within $0.5 \mathrm{sec}$, while the engine load remained constant during this period at 900 $\mathrm{Nm}$ (full load). The subsequent reduction of engine brake torque to approximately $150 \mathrm{Nm}$ caused rapid engine crankshaft deceleration, with the engine speed reaching $900 \mathrm{rpm}$ at $0.5 \mathrm{sec}$. As a result, the engine airflow was greatly decreased. Simultaneously, both the turbocharger speed and the inlet manifold pressure were reduced too, since the energy content of the exhaust gases at the turbine entrance was low, but not as abruptly as the engine airflow. As a result, the compressor operating point proceeded towards the surge line, as depicted in Figure 9. Soon after $0.5 \mathrm{sec}$, the compressor operating point had moved along the stable region of the compressor map and surging was generated.

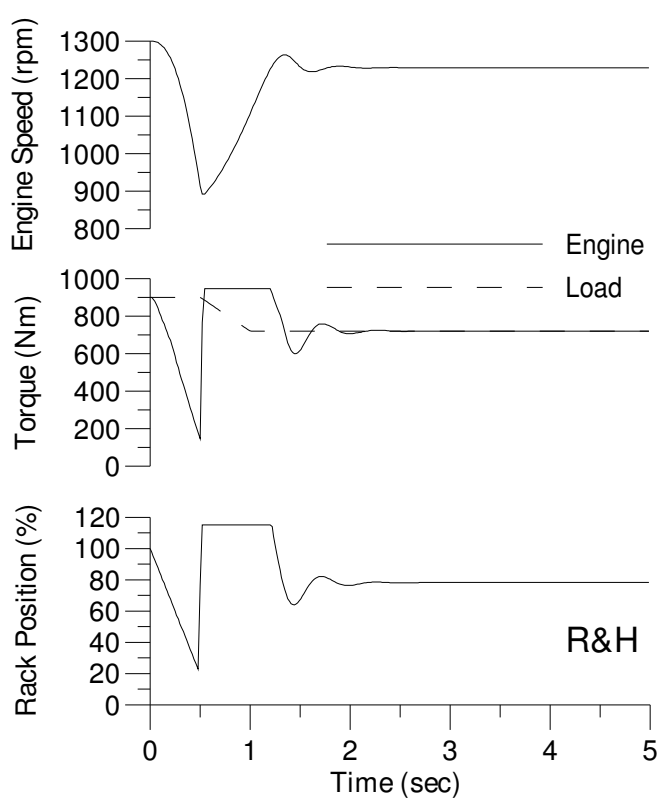

Figure 7. Predicted engine parameters for a rapid fuel supply reduction.

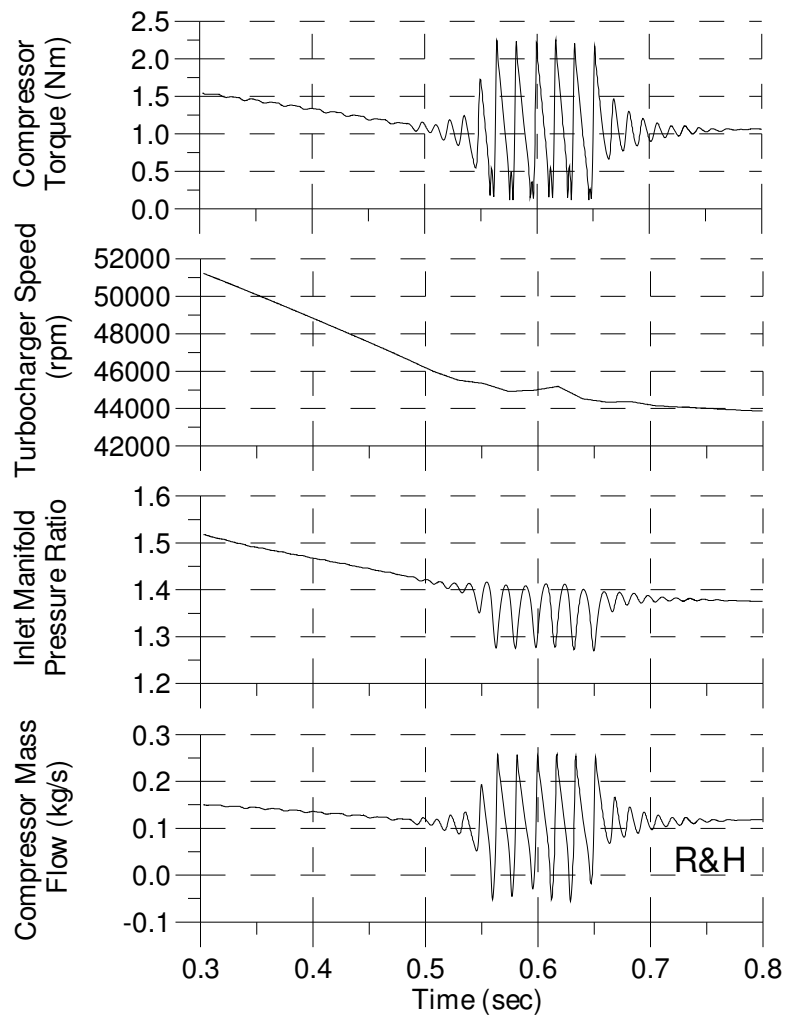

Figure 8. Predicted compressor parameters for a rapid fuel supply reduction.

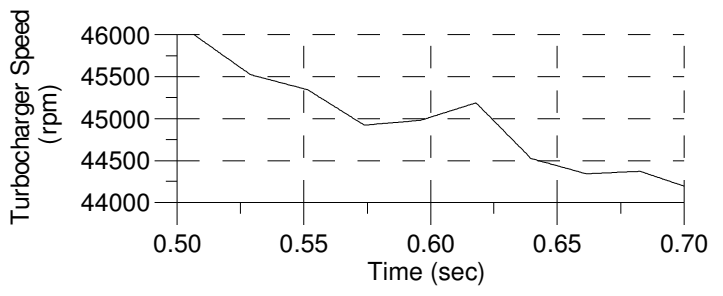

Figure 8a. Enlargement of turbocharging speed oscillation of Figure 8 for the critical time period of surge. 


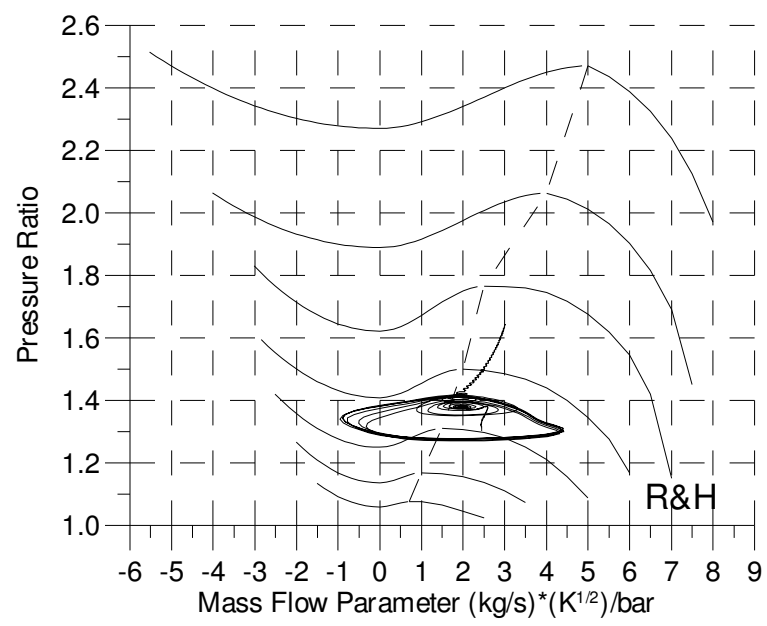

Figure 9. Predicted trajectory of inlet manifold to ambient pressure ratio against compressor mass flow parameter on compressor map, for a rapid fuel supply reduction.

Then, the engine load dropped linearly from $100 \%$ to $80 \%$, corresponding to $720 \mathrm{Nm}$ within another $0.5 \mathrm{sec}$, while the engine speed governor took control of the rack position from that moment on, and consequently the fuel pump determined the appropriate quantity of fuel to be injected into the engine cylinders in order to match the load torque. Compressor surging continued until almost $0.7 \mathrm{sec}$, when the turbocharger speed and inlet manifold pressure sufficiently dropped and the operating point reentered the compressor stable zone, in order to be stabilized to a new steady operating condition.

As shown in Figure 8, during the compressor surging the torque absorbed by the compressor impeller rapidly varied, due mainly to the air flow reversals. In this way, severe torsional loadings were introduced to the turbocharger shaft. So, it is evident that such air flow, inlet manifold pressure and turbocharger shaft torque oscillations can harmfully influence both the engine and turbocharger operation. In the examined case, compressor surging lasted only approximately $0.2 \mathrm{sec}$, and therefore it cannot practically affect the engine safe running. However, if compressor surging continuously occurs, the engine and turbocharger safe running can be adversely affected.

It is made clear here too that the second small fluctuation at the bottom of each torque fluctuation of Figure 8 is caused by the use of Equation (11) for the positive compressor flow area and the suggestion that the even extension of Equation (11) is applied for the negative compressor flow area. As the operating point reaches compressor zero mass flow point, compressor absorbed torque takes its minimum value. Proceeding to negative mass flow rates, the torque increases, until the peak of the second small fluctuation, where the operating point changes direction on the compressor map to increased mass flow rates. During its path to compressor zero mass flow point again from negative mass flow rates, the torque drops again until its minimum value, and then it rises again as the operating point takes continuously increased positive values of mass flow rates. This second fluctuation does not seem to significantly affect the overall results, except that the turbocharger shaft is subject to more intense torsional loading.

At first view of Figure 8, it seems that the turbocharger speed does not oscillate along with the mass flow rate and pressure ratio. Yet, it is a matter of scale of Figure 8, and for that reason Figure $8 a$ is given, which is actually an enlargement of the turbocharging speed oscillation of Figure 8 for the critical time period of surge. It is shown that turbocharger speed has indeed a tendency to oscillate, but this trend becomes weaker due to its continuous drop during the whole transient operation.

Another special case that could drive the turbocharger compressor of a diesel engine to exhibit surge is a rapid change of engine loading. When the engine operates at high load and suddenly this drops, while almost immediately it rises again, the engine speed rapidly decreases. As a result, the engine airflow is reduced too and the compressor operating point, which was already close to the surge line since the engine was operating at high load, moves to the unstable zone of the compressor map.

The simulated engine operation case includes initially the engine running at full load and $1200 \mathrm{rpm}$. Then, the load is rapidly reduced to $10 \%$ and very soon it is increased again to $80 \%$. It was decided that this engine transient operation would occur at constant engine speed, in order to be differentiated from the previous simulated case, where it did not remain constant. For that purpose, the integral term in Equation (15) in the governor simulation was incorporated.

The predicted engine parameters that describe this transient load change are shown in Figure 10, while the predicted compressor parameters in Figure 11. Firstly, the engine speed was increased due to the load decrease. Thus, the engine airflow was increased too and the compression system operating point moved towards the choke region. The predicted trajectory of the compression system operating point on the compressor map is depicted in Figure 12. After that, the engine load was increased again, causing the rapid drop of engine speed, which almost reached the value of $800 \mathrm{rpm}$. At that moment, $0.6 \mathrm{sec}$, compressor surging started, as the compressor operating point was driven beyond the surge line.

As the engine speed governor responded in order to meet the demand of $1200 \mathrm{rpm}$ at $80 \%$ load, more fuel mass was injected into the engine cylinders, the engine brake torque was increased, the engine speed followed that increase and consequently the engine air flow was increased too. Thus, little after $0.8 \mathrm{sec}$, the compression system operating point moved back again into the stable compressor region. 


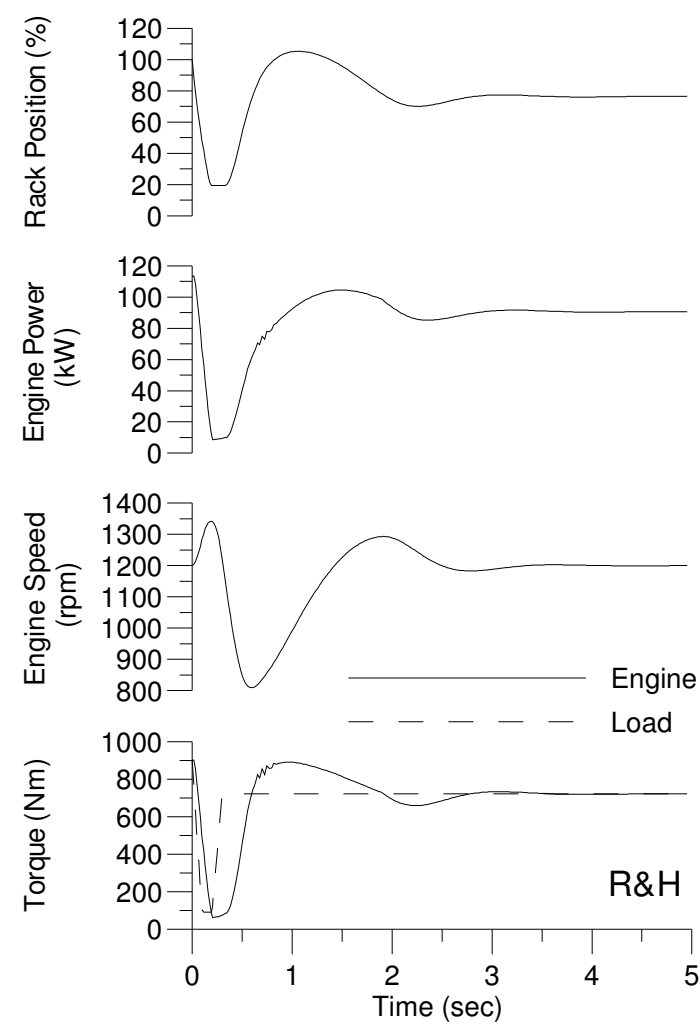

Figure 10. Predicted engine parameters for rapid load changes of $100 \%-10 \%-80 \%$.

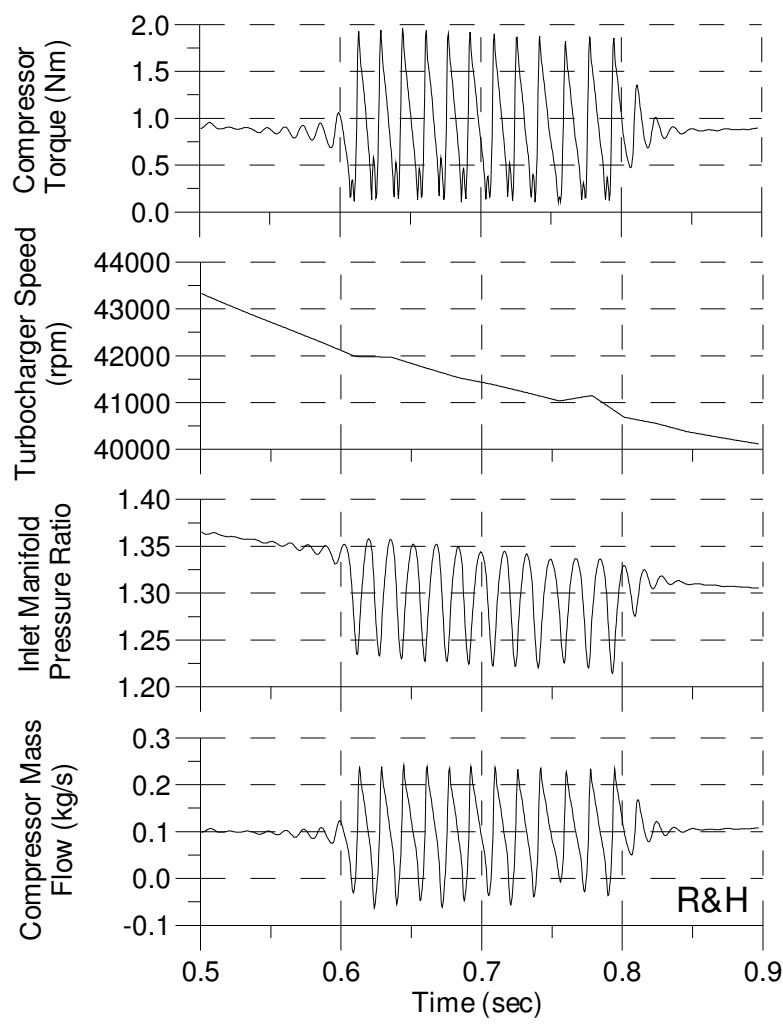

Figure 11. Predicted compressor parameters for rapid load changes of $100 \%-10 \%-80 \%$.

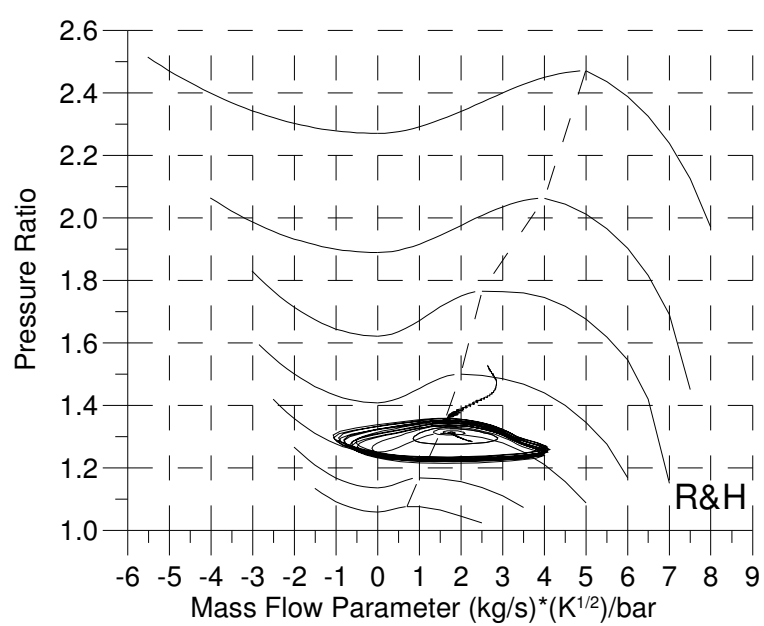

Figure 12. Predicted trajectory of compression system operating point on the compressor map, for rapid load changes of $100 \%-10 \%-80 \%$.

\section{Parametric study of surge}

After these two simulation cases of compressor surging, a parametric study was carried out in order to investigate the effect of some compression system geometric elements on surge pattern. These were the volume of the engine inlet manifold and the length of the compressor equivalent duct. Some relevant results of the influence of inlet manifold volume on the form of surge cycles were reported in [1-4], while consideration concerning the connection between surge loops and compressor duct length can be found in [1] and [3]. The engine transient operation case, which was decided to be used for this analysis, was the one caused after the rapid reduction in fuel supply.

Figures 13 and 14 present the predicted compressor parameters and trajectory of the compression system operating point on the compressor map, respectively, resulting from an increase of the engine inlet manifold volume five times up, while all other parameters remained constant. They can be easily compared to Figures 8 and 9, respectively, which concern transient compression system behavior with the actual volume of inlet manifold.

As earlier researchers have observed, it is established here too that the volume of the intake manifold does not really affect the amplitude of the compressor mass flow and pressure rise oscillations, when compressor surging is progressing. On the contrary, the frequency of the surge cycles is altered, becoming lower with volume increase.

In Figure 15, which is actually an enlargement of a part of Figure 13 including also a portion of the surge loops of Figure 14, the shape and character of the occurring oscillations are clearly deconvoluted. 


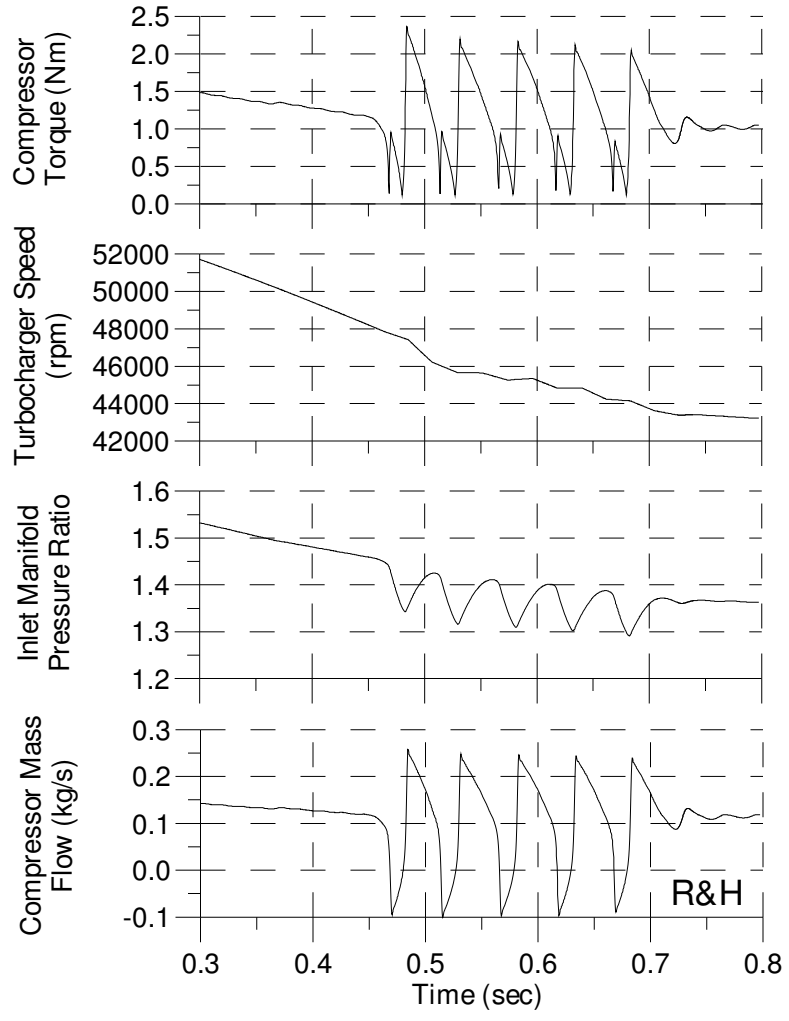

Figure 13. Predicted compressor parameters for an increase of inlet manifold volume of five times up and a rapid fuel supply reduction.

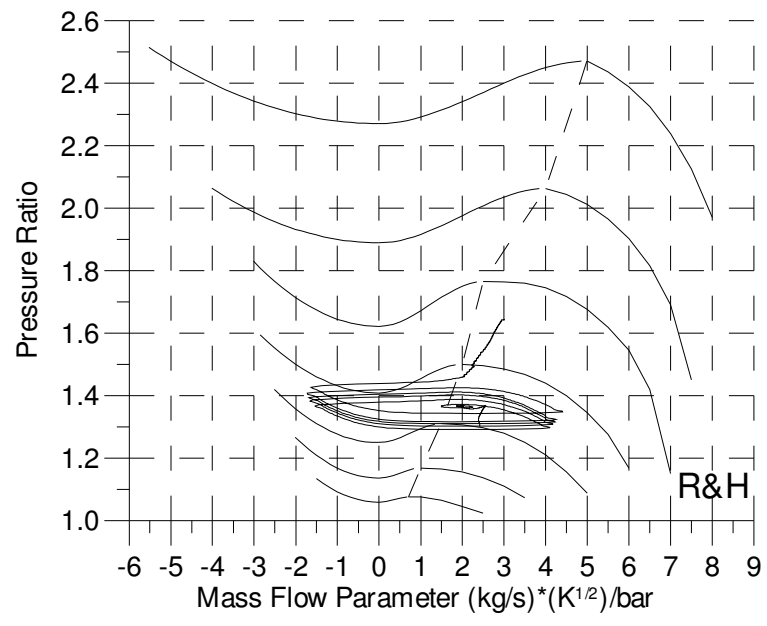

Figure 14. Predicted trajectory of compression system operating point on the compressor map for an increase of inlet manifold volume of five times up and a rapid fuel supply reduction.

Two different time scales are noticed. First, a long one, when the compression system operating point moves along the steady state characteristics, from point II to point III (inlet manifold pressure building up) and from point IV to point I' (inlet manifold discharging). During these periods, the mass flow through the compressor changes gradually. Firstly, within the period of inlet manifold pressure building up, compressor mass flow drops, while the compression system operating point moves in the stable compressor region. Then, during the inlet manifold blowdown period, compressor mass flow rises again, from negative to positive values, with the compression system operating point moving mainly along the steady negative flow portion of the compressor characteristic. These two similar but discrete periods, which determine the filling and emptying time requirements of the inlet manifold, actually define also the surge cycle period.
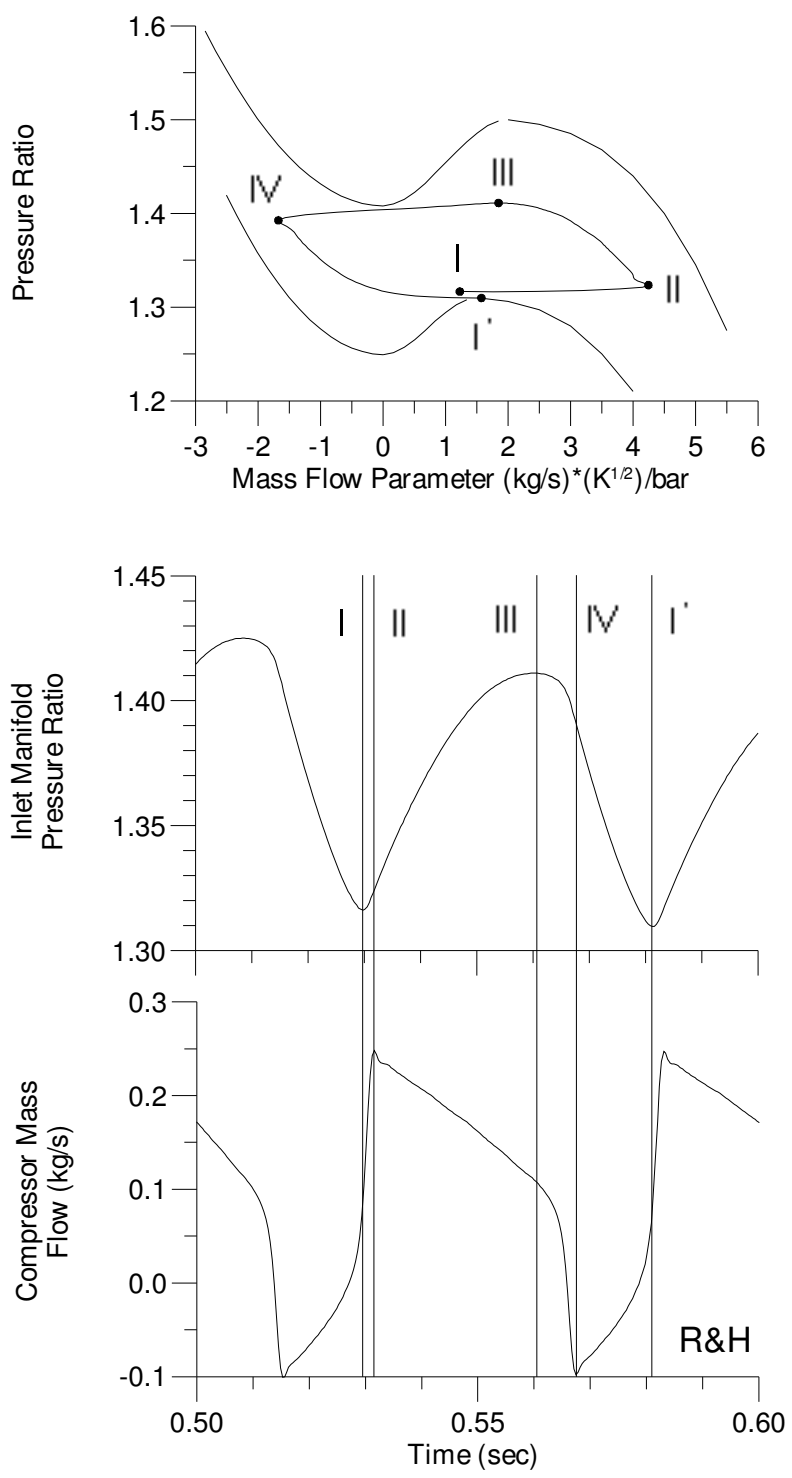

Figure 15. Details of simulation results for the understanding of surge oscillations.

The other short time scale observed characterizes the two remaining parts of the surge loop, motions III-IV and I-II of the operating point, where the mass flow changes rapidly at almost constant pressure. It is noted that the shorter time period during the surge oscillations is the one the operating point spent while moving along regions of the compressor map other than those of steady flow characteristics. This actually confirms the already mentioned statement that the compression system operating point passes through these areas very rapidly.

It is noted that the increase of the inlet manifold volume facilitated the derivation of these additional considerations, regarding the description of the various stages of the surge cycles. This was due to the fact that the completion of the surge loops needed longer time 
periods, thus providing convenience for detailed observations.

Finally, in order to examine the influence of the length of the compressor equivalent duct on the compressor mass flow and pressure rise fluctuations form, an additional run was performed reducing by half this length.

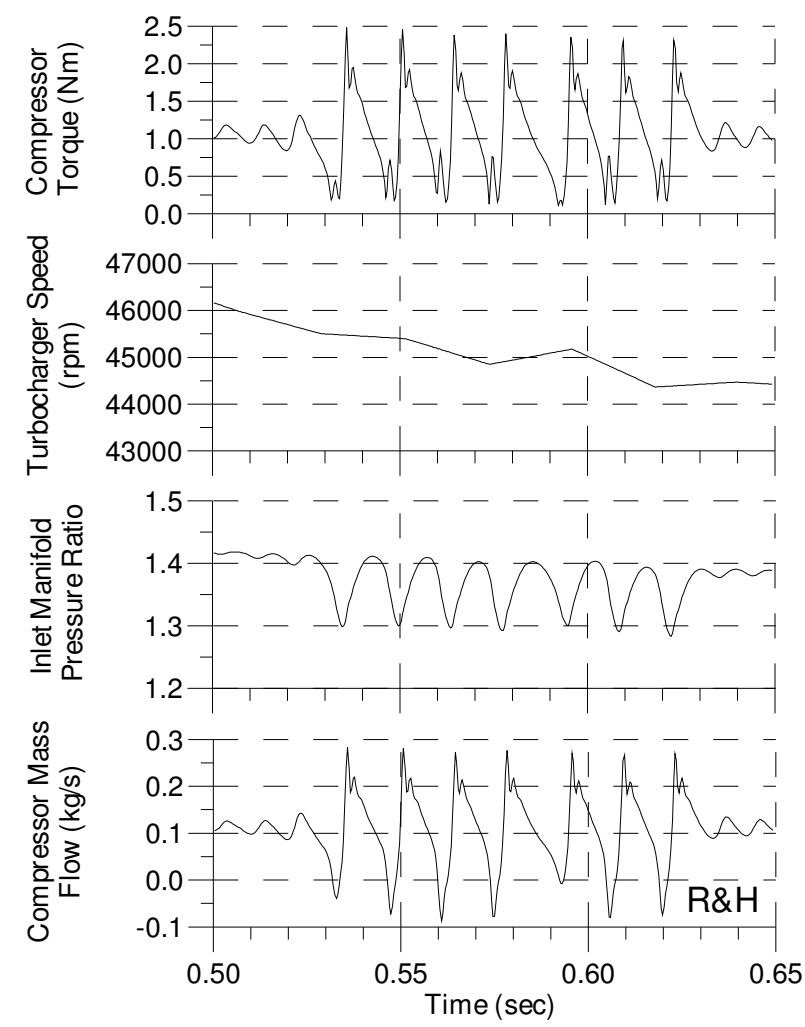

Figure 16. Predicted compressor parameters for reduction of compressor equivalent duct length by half and a rapid fuel supply reduction.

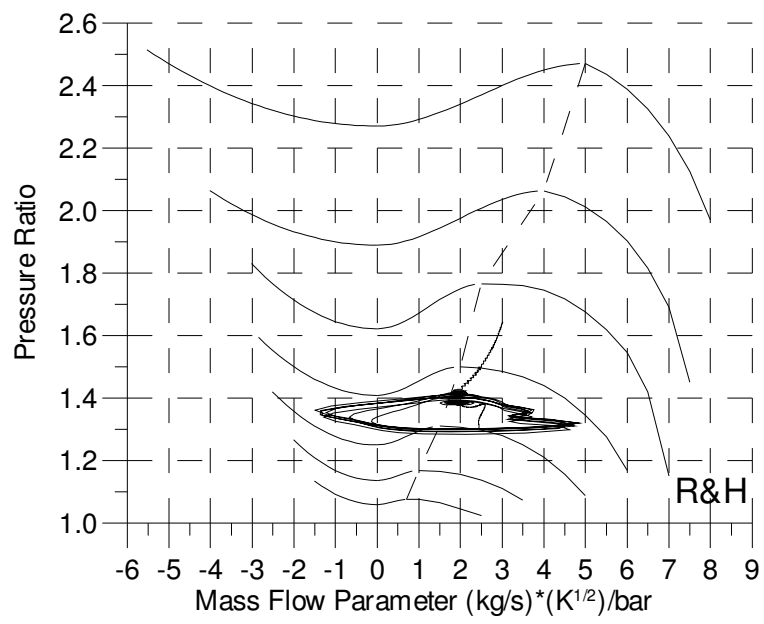

Figure 17. Predicted trajectory of compression system operating point on the compressor map for reduction of compressor equivalent duct length by half and a rapid fuel supply reduction.

The predicted compressor parameters and the trajectory of the compression system operating point on the compressor map are shown in Figures 16 and 17, respectively, which can be easily compared to Figures 8 and 9, respectively, which concern transient compression system behavior with the actual length of compressor equivalent duct.

As is clearly noted, neither the amplitude of the compressor mass flow and pressure rise oscillations nor the surge frequency are basically changed. The only difference that can be observed is that the time period surge is occurring is now a little shorter.

Moreover, during the motion of the compression system operating point along the positive stable portion of the compressor characteristic, a small deviation towards increased air mass flows appears. However, this movement is quickly reformed by the point tendency to pass to the compressor negative flow zone. Reduction of compressor duct length seems to make the phenomenon more severe, introducing a higher frequency oscillation at the top of each mass flow rate fluctuation. Getting information from the open literature, one can see that not all of the mass flow rate oscillations during surge have exactly the same shape with these presented at Fig. 8, 11 and 13, partially depending on the whole compression system geometry. Actually, there are cases where higher frequency oscillations are noticed, like in Fig. 16. Regarding the torque oscillation, it was explained before how it follows the mass flow rate oscillation.

Moreover, additional runs showed that excessive increase of compressor equivalent duct length causes no surging initiation of the system, while it must be noted that in that case the effect of pressure waves along the duct could not be neglected.

\section{MWM TbRHS 518S ENGINE}

A similar to the previously conducted analysis, for the Ruston \& Hornsby engine, was also conducted for the MWM engine.

\section{Steady state}

The steady state operating points of the MWM engine at full load were derived too, using the developed simulation code. It is noted here that only the predicted engine operating line at full load superimposed on the compressor map is presented in Figure 18, while various engine parameters characterizing the engine overall performance are not given here for the sake of brevity of space of this paper.

Detailed simulation and experimental study of the engine steady state and transient operation, as well as examination of the various engine parameters effect on the engine performance, has already been conducted for this engine by the research group headed by the first author, in previous works. It is extensively reported in [18-23]. 


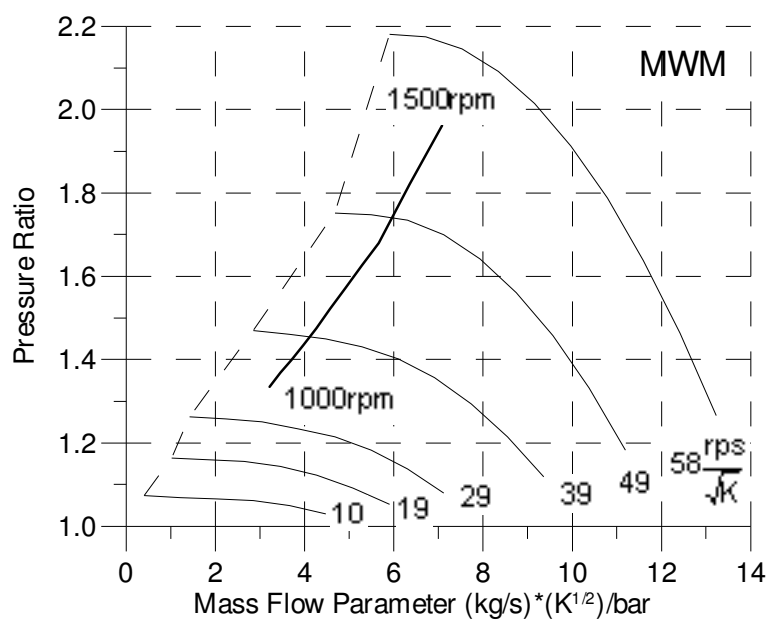

Figure 18. Predicted engine full load operating line on the compressor map.

It is concluded, for this case of turbocharged diesel engine too, that the matching with the turbocharger is satisfactory along the whole engine speed range. However, when the engine is forced to run under extreme transient operating conditions, like the ones that are described afterwards, it results that the surge margin is not always adequate for preventing surge occurrence.

\section{$\underline{\text { Transients with surge }}$}

For the examination of the engine transient behavior under conditions generating compressor surging, the two, already mentioned for the Ruston \& Hornsby engine, operating cases were simulated. Firstly, the case where the turbocharger compressor is driven into its unstable region after an abrupt reduction in fuel supply is presented. Then, a critical for surging initiation transient run is performed, in which very sudden load changes are imposed.

Figures 19 and 20 present simulation results of the engine and compressor transient behavior after a rapid drop of fuel supply. The engine was initially operating at full load and $1200 \mathrm{rpm}$, when the rack position quickly dropped to $20 \%$. After this period, the engine speed had already decreased, due to the deficit of the engine torque in comparison with the load torque. At that moment, the governor responded to meet the demand of $91 \%$ load, which was imposed in the meantime.

Surge initiated when the engine speed had dropped to its minimum value and the inducted air flow was not sufficient to prevent the generation of this phenomenon. The predicted trajectory of the compression system operating point on the compressor map is shown in Figure 21.

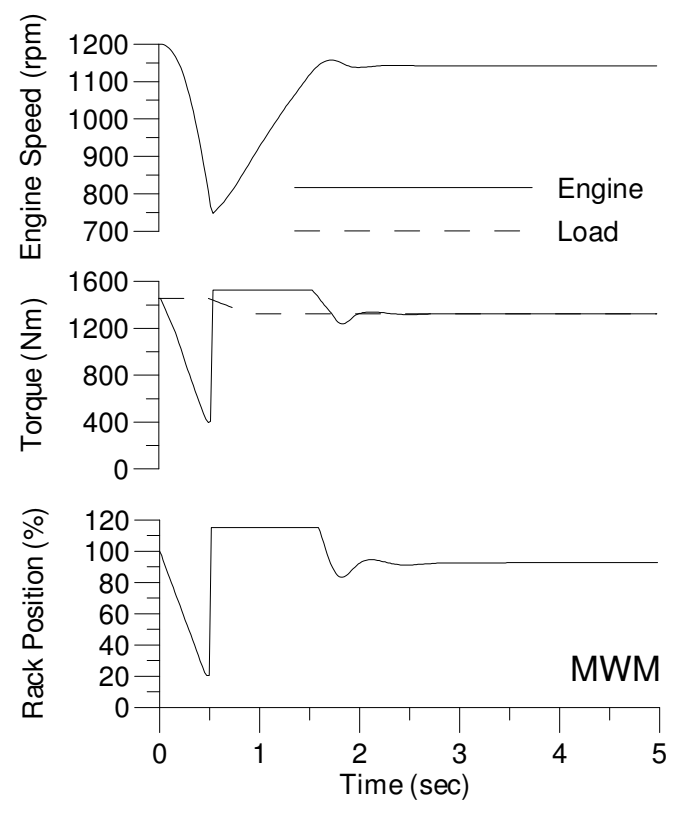

Figure 19. Simulation results of engine transient behavior after a rapid drop of fuel supply.

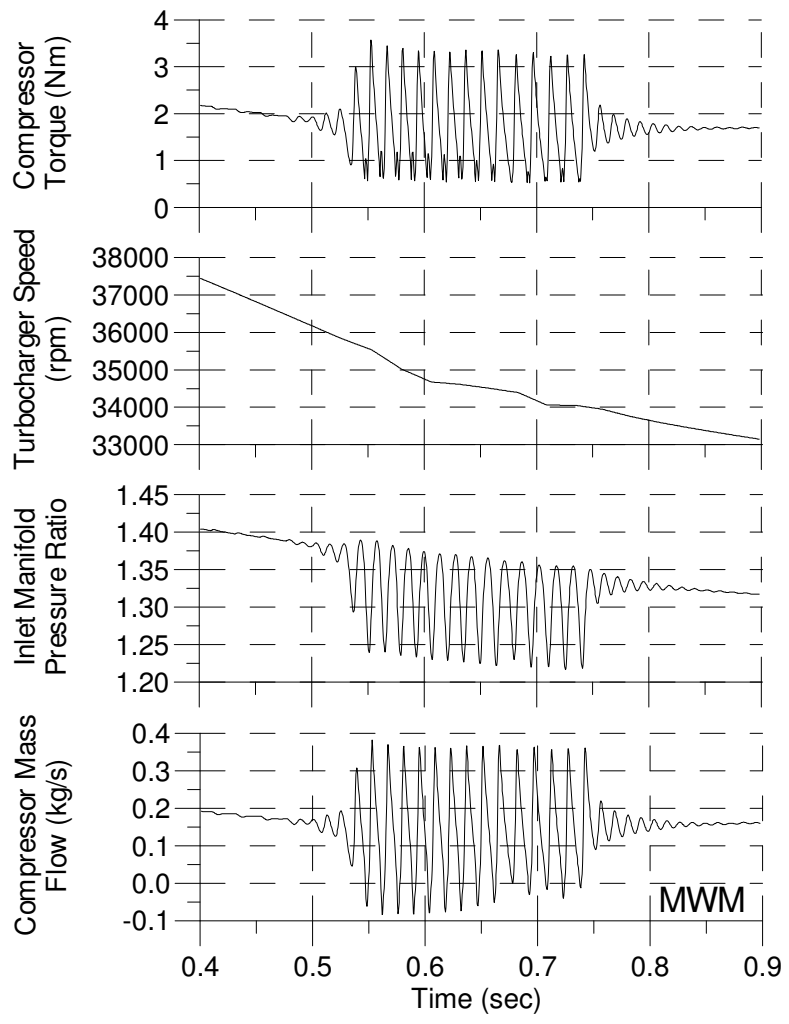

Figure 20. Simulation results of compressor transient behavior after a rapid drop of fuel supply. 


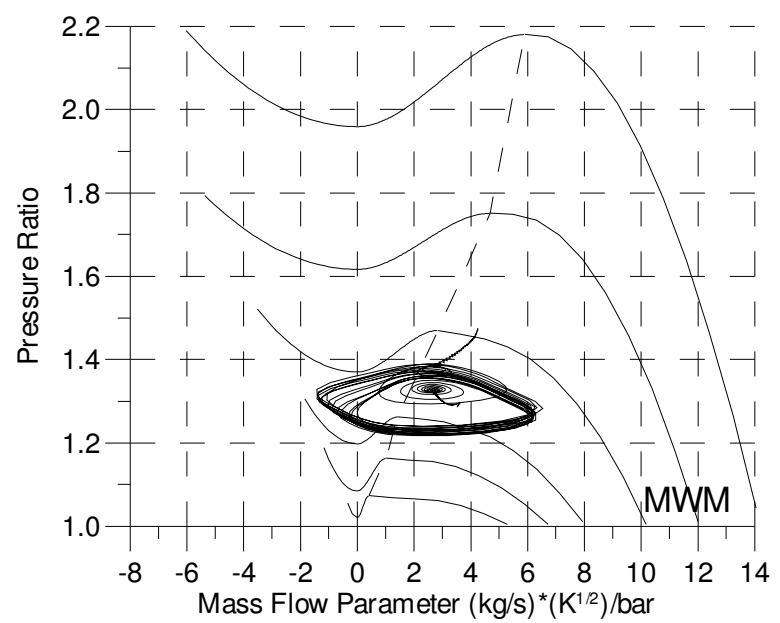

Figure 21. Predicted trajectory of compression system operating point on the compressor map after a rapid drop of fuel supply.

Afterwards, the other surge resulting transient operation case was simulated too. Initially, the engine was running at full load and $1200 \mathrm{rpm}$, when it quickly dropped to $9 \%$ and almost immediately it was increased again to $91 \%$. The predicted simulation results for the engine and compressor parameters transient response are shown in Figures 22 and 23, respectively, while the predicted trajectory of the compression system operating point on the compressor map is shown in Figure 24.

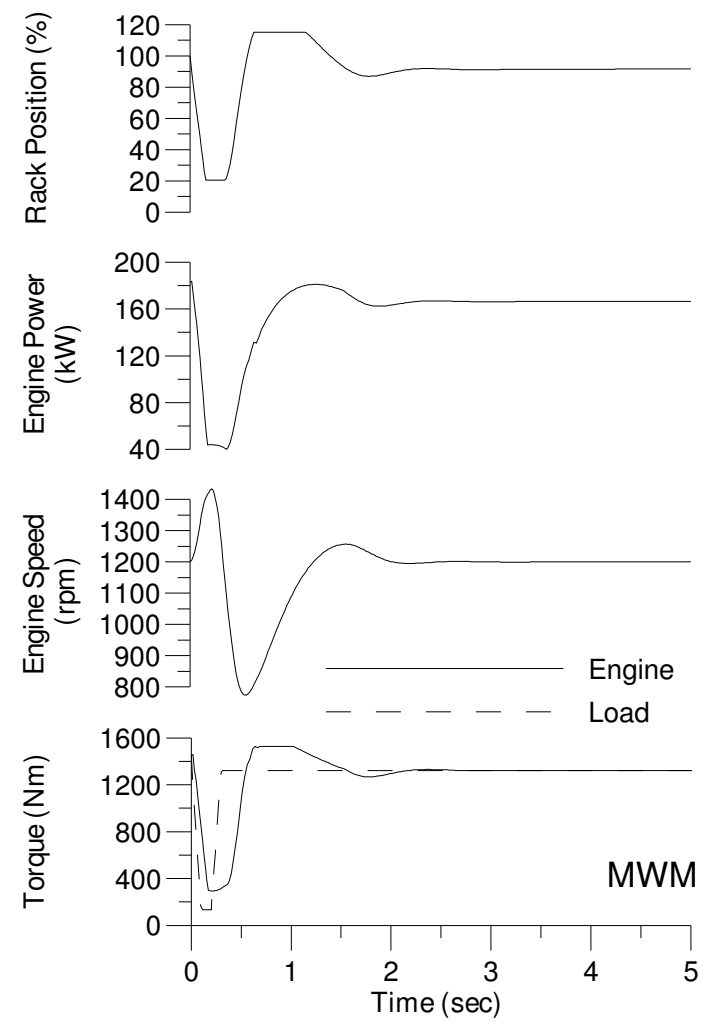

Figure 22. Simulation results of engine transient response for rapid load changes of $100 \%-9 \%-91 \%$.

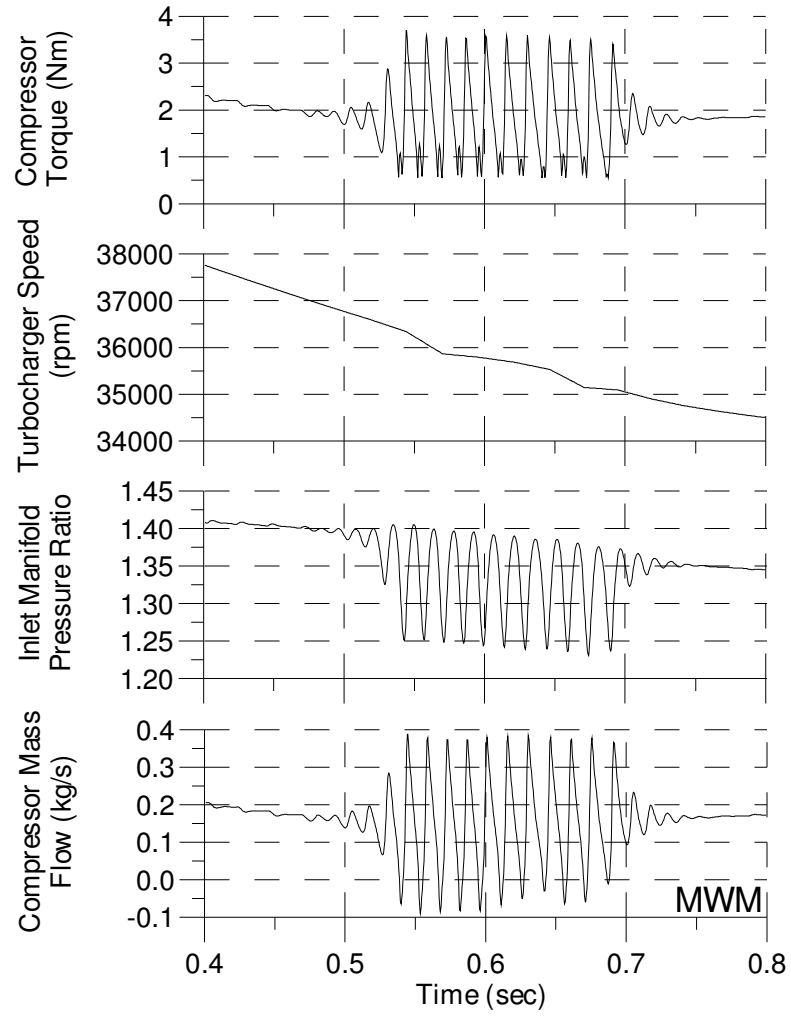

Figure 23. Simulation results of compressor transient response for rapid load changes of $100 \%-9 \%-91 \%$.

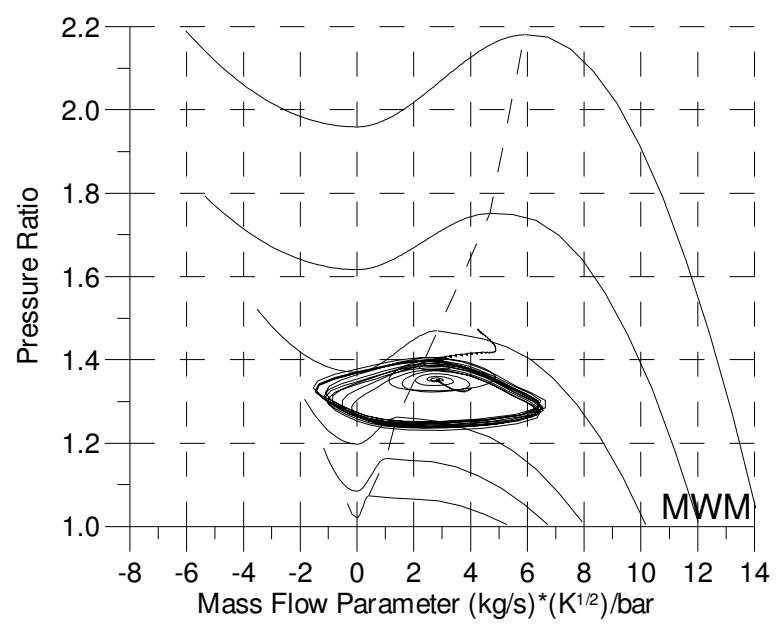

Figure 24. Predicted trajectory of compression system operating point on the compressor map for rapid load changes of 100\%-9\%-91\%.

Initially, because of the sudden load drop, the engine speed was increased and thus the compression system operating point moved towards the choke region. Then, the following increase of the load resulted in subsequent rapid engine speed decrease and therefore entering of the operating point into the compressor unstable zone. Surge cycles developed, until finally the governor response to the increased load permitted the injection of more fuel mass into the cylinders, increasing the engine torque and consequently the engine speed, driving the operating point back again into the useful operational area of the compressor map. 


\section{CONCLUSIONS}

A model predicting the transient response of a turbocharged diesel engine air-charging system was developed, in order to investigate turbocharger compressor instability behavior during surge conditions. The model was then included into a linearized quasisteady engine simulation code.

Two different engine operation cases, responsible for inducing compressor surging, were simulated. The overall simulation code was first applied to an automotive, light duty, turbocharged diesel engine and then to a marine duty diesel one, for examining the transient engines operation during the development of this complex phenomenon. The scope of this work was to achieve adequately accurate results through the simplicity of the used model.

Firstly, it was found that when the engine runs close to or at full load, a rapid reduction in fuel supply can drive the compressor into its unstable region, due to the abrupt drop of engine air flow, following the decrease of engine speed, and the simultaneously slower response of turbocharger operation.

Then, additional transient runs were performed, with imposed dangerous load profiles for compressor surging initiation. These special operating conditions, including sudden load changes between extreme high and low limits, can cause functioning of compressor beyond its stable limit, when the engine operates at full load and the compression system point lies close enough to the surge line.

Furthermore, the effect of the engine inlet manifold volume on the surge pattern was examined. It was found that the volume of the inlet manifold does not influence the amplitude of the compressor mass flow and pressure rise oscillations, but defines the surge cycles frequency. Specifically, an increase of the inlet manifold volume results to reduction of the loops frequency.

Regarding changes of compressor duct length, it was shown that these have no traceable effects either on the amplitude of the oscillations or the surge cycle period, when these changes vary between reasonable limits. Though, it was observed that excessive increase of compressor duct length tended to produce no instability occurrence.

\section{REFERENCES}

1. Yano, T. and Nagata, B.I., 'A study on surging phenomena in diesel engine air-charging system', Japan Society of Mechanical Engineers, Vol. 14, pp. 364-376, 1971.

2. Greitzer, E.M., 'Surge and rotating stall in axial flow compressors. Part I: Theoretical compression system model', Transactions ASME, Journal of
Engineering for Gas Turbines \& Power, Vol. 98, pp. 190-198, 1976.

3. Greitzer, E.M., 'Surge and rotating stall in axial flow compressors. Part II: Experimental results and comparison with theory', Transactions ASME, Journal of Engineering for Gas Turbines \& Power, Vol. 98, pp. 199-217, 1976.

4. Hansen, K.E., Jørgensen, P. and Larsen, P.S., 'Experimental and theoretical study of surge in a small centrifugal compressor', Transactions ASME, Journal of Fluids Engineering, Vol. 103, pp. 391-395, 1981.

5. Fink, D.A., Cumpsty, N.A. and Greitzer, E.M., 'Surge dynamics in a free-spool centrifugal compressor system', Transactions ASME, Journal of Turbomachinery, Vol. 114, pp. 321-332, 1992.

6. Chesse, P., Hetet, J.F., Tauzia, X., Roy, P. and Inozu, B., 'Performance simulation of sequentially turbocharged marine diesel engines with applications to compressor surge', Transactions ASME, Journal of Engineering for Gas Turbines \& Power, Vol. 122, pp. 562-569, 2000.

7. Theotokatos, G. and Kyrtatos, N.P., 'Diesel engine transient operation with turbocharger compressor surging', SAE Paper No 2001-01-1241, 2001.

8. Heywood, J.B., Internal Combustion Engines Fundamentals, New York, Mc-Graw Hill, 1988.

9. Theotokatos, G. and Kyrtatos, N.P., 'Investigation of a large high speed-diesel engine transient behavior including compressor surging and emergency shutdown', Transactions ASME, Journal of Engineering for Gas Turbines \& Power, Vol. 125, pp. 580-589, 2003.

10. Moore, F.K. and Greitzer, E.M., 'A theory of post-stall transients in axial compression systems. Part I: Development of equations', Transactions ASME, Journal of Engineering for Gas Turbines \& Power, Vol. 108, pp. 68-76, 1986.

11. Botros, K.K., 'Transient phenomena in compressor stations during surge', Transactions ASME, Journal of Engineering for Gas Turbines \& Power, Vol. 116, pp. 133-142, 1994.

12. Horlock, J.H. and Winterbone, D.E., The Thermodynamics and Gas Dynamics of Internal Combustion Engines, Vol. II, Clarendon Press, Oxford, 1986.

13. Watson, N. and Janota, M.S., Turbocharging the Internal Combustion Engine, MacMillan, London, 1982.

14. Ferguson, C.R., Internal Combustion Engines, Wiley, New York, 1986.

15. Benson, R.S. and Whitehouse, N.D., Internal Combustion Engines, Pergamon Press, Oxford, 1979.

16. Benson, R.S., Ledger, J.D., Whitehouse, N.D. and Walmsley, S., 'Comparison of experimental and simulated transient responses of a turbocharged diesel engine', SAE Paper No 730666, 1973.

17. Winterbone D.E., Benson R.S., Mortimer, A.G., Kenyon, P. and Stotter, A., 'Transient response of 
turbocharged diesel engine - Part 1 \& Part 2', SAE Paper No 770122, 1977.

18. Kouremenos, D.A., Rakopoulos, C.D. and Andritsakis, E.C., 'Theoretical and experimental investigation of the wave action in the exhaust system of a multi-cylinder turbocharged marine IDI diesel engine', Proceedings, ASME-WA Meeting, New Orleans LA, AES, Vol. 30, pp. 337-354, 1993.

19. Rakopoulos, C.D. and Giakoumis, E.G., 'Development of cumulative and availability rate balances in a multi-cylinder turbocharged indirect injection diesel engine', Energy Conversion \& Management, Vol. 38, pp. 347-369, 1997.

20. Rakopoulos, C.D., Giakoumis, E.G. and Hountalas, D.T., 'Experimental and simulation analysis of the transient operation of a turbocharged multi-cylinder IDI diesel engine', Energy Research, Vol. 22, pp. 317-331, 1998.

21. Rakopoulos, C.D. and Giakoumis, E.G., 'Availability analysis of a turbocharged diesel engine operating under transient load conditions', Energy-The International Journal, Vol. 29, pp. 1085-1104, 2004.

22. Rakopoulos, C.D., Giakoumis, E.G., Hountalas, D.T. and Rakopoulos, D.C., 'The effect of various dynamic, thermodynamic and design parameters on the performance of a turbocharged diesel engine operating under transient load conditions', SAE Paper No 2004-01-0926, 2004.

23. Rakopoulos, C.D., Giakoumis, E.G. and Rakopoulos, D.C., 'The effect of friction modelling on the prediction of turbocharged diesel engine transient operation', SAE Paper No 2004-01-0925, 2004.

\section{NOMENCLATURE}

A compressor equivalent duct area, $\mathrm{m}^{2}$

I moment of inertia, $\mathrm{kg} \mathrm{m}^{2}$

k PI control law constants

$\ell \quad$ length, $m$

$L_{c} \quad$ compressor equivalent duct length, $m$

m mass, $\mathrm{kg}$

$\dot{\mathrm{m}}$ mass flow rate, $\mathrm{kg} \mathrm{s}^{-1}$

$\mathrm{M}$ torque, $\mathrm{N} \mathrm{m}$
$\mathrm{N} \quad$ rotational speed, rpm

$\mathrm{p}$ pressure, $\mathrm{Pa}$

pr compressor pressure ratio

$\mathrm{q}$ rack position, $\mathrm{mm}$

$\mathrm{R}$ specific gas constant, $\mathrm{J} \mathrm{kg}^{-1} \mathrm{~K}^{-1}$

$\mathrm{t}$ time, $\mathrm{s}$

$\mathrm{T}$ temperature, $\mathrm{K}$

$\mathrm{v}$ volume, $\mathrm{m}^{3}$

$\mathrm{z}$ number of cylinders

\section{Greeks}

$\beta \quad$ compressor characteristic parameter

$\gamma \quad$ ratio of specific heat capacities

$\varepsilon \quad$ air cooler effectiveness

$\eta \quad$ isentropic efficiency

$\lambda$ scavenge ratio

$\tau_{\mathrm{g}} \quad$ speed governor time constant, $\mathrm{s}$

$\varphi \quad$ compressor characteristic parameter

$\omega \quad$ angular speed, $\mathrm{rad} \mathrm{s}^{-1}$

\section{Subscripts}

0 conditions at compressor zero mass flow

a ambient

ac air cooler

b brake

c compressor

cool coolant medium

dem demanded

$\mathrm{E}, \mathrm{e}$ engine

i inlet manifold

ivc inlet valve closing

I I-constant

$\ell \quad$ load

P P-constant

t turbine

tot total

TC turbocharger 